\title{
Comparison of Turkey and Bulgaria's Health Systems
}

Türkiye ve Bulgaristan'ın Sağlık Sistemlerinin Karşılaştırılması

Rujnan Tuna (D)

SHYD 2021;8(1):118-124

doi:10.5222/SHYD.2021.66487

Cite as: Tuna R. Türkiye ve Bulgaristan'ın sağlık sistemlerinin sarşılaştırılması. Sağlık ve Hemşirelik Yönetim Dergisi. 2021;8(1):118-124.

\section{Öz}

Sağlık sistemi, sağlığı geliştirmek amacına yönelik her türlü hizmeti barındıran girdi, süreç, çıktı ve sonuç bileşenlerinden oluşan bir bütündür. Günümüzde ülkeler sağlık sistemlerinin etkinliği sürdürürken, sağlık harcamalarını da kontrol edebilmek için farklı sağlık sistemleri geliştirmişlerdir. Bu çalışmada, Türkiye ve Bulgaristan'ın sağlık sistemlerinin karşılaştırılması amaçlanmıştır. Çalışmada; Türkiye'nin nüfus yapısının Bulgaristan'a göre çok daha genç olduğu belirlenmiş olmakla birlikte, Türkiye'deki hastane sayısının daha fazla olmasına karşın kişi başına düşen hastane yatak sayısı ve sağlık çalışanı oranının Bulgaristan'a oranla daha düşük olduğu saptanmıştır. Türkiye'de sağlık hizmetinin devlet güvencesi kapsamında tüm vatandaşlara ulaștırılması amaçlanmış iken Bulgaristan'da bireysel sağlık sözleşmeleri ile düşük gelirli vatandaşların kapsam dıșı bırakıldığı görülmüștür. Ayrıca, Türkiye'de sağlık hizmetlerinin sunumu devlet sorumluluğunda yürütülürken, Bulgaristan'da sağlık hizmetinin devlet sorumluluğundan çok bireylerin ödediği bireysel primler ile satın alındığı belirlenmiştir.

Anahtar kelimeler: Bulgaristan, sağlık sistemi, Türkiye

\section{Abstract}

The health system as a whole consists of inputs, processes, outputs and result elements that are contained within all kinds of services in order to improve health. Today, countries have developed different health systems in order to control the health expenditures while maintaining the effectiveness of health systems. The aim of this study was to compare the infrastructure of health systems in Turkey and Bulgaria. Population of Bulgaria is much younger compared to Turkey's population. However, although higher number of hospitals are located in Turkey; the number of hospital beds per person and the proportion of healthcare workers are lower than that of Bulgaria. It was also observed that the aim is to ensure a state guarantee to all citizens within the scope of health services in Turkey. However, in Bulgaria, it was observed that low income citizens were excluded from these services by individual health contracts. While the provision of health services in Turkey is carried out under state responsibility, in Bulgaria provision of health services is not under state responsibility but these services are purchased with premiums paid by individuals.

Keywords: Bulgaria, health system, Turkey
Recieved / Geliş:

26.12.2020

Accepted / Kabul:

19.03.2020

Published Online / Online Yayın: 28.04.2021

Corresponding author /

Sorumlu yazar:

Rujnan Tuna

İstanbul Medeniyet Üniversitesi, Sağlık Bilimleri Fakültesi, Hemşirelik Bölümü, Hemşirelikte Yönetim Anabilim Dalı, İstanbul, Türkiye

rujnantuna@yahoo.com ORCID: 0000-0002-5156-3781 


\section{Sağlık sistemlerinin karşılaştırılması}

Comparison of health systems

\section{Extended Abstract}

The healthcare system is a complex structure that covers many areas including the provision of health services, financing, training of the health workforce, and determination of health policies. Today, countries adopt many different health system models. In some countries, health services are fully financed by the state. In other countries, health services are left to the mercy of market conditions. In many countries, health systems are offered in a mixed structure.

Today, countries have developed different models to keep people healthy and to control health expenditures. There are four main models accepted all over the world including The Beveridge model e.i. Bismarck model, the national health insurance model and the out-of-pocket payment model. The main difference that separates these models from each other is related to the institution/authority that will finance the health services. However, nowadays, health financing has become an increasingly complex issue which means that health financing is offered through taxes, social security premiums, outof-pocket payments and private health insurances.

Presentation of health services in Turkey is one of the state's duty and the Ministry of Health is responsible for health services. Health services are provided by public, semi-public, private and non-profit foundation organizations. Health services are financed by taxes, social security premiums (SGK), private insurance premiums and out-of-pocket payments. As of 2012, the obligation for all citizens to be included in the General Health Insurance system was introduced (Comez, Demirkiran, and Bahar, 2020).

The health system of Bulgaria is also carried out by the policies determined by the Ministry of Health. At the district level, health policies are organized and implemented by the Regional Health Inspection Units. The state owns $51 \%$ of all hospitals and health institutions providing health services in the country. With the Health Insurance Law enacted in 1998, the Bulgarian health system became a health insurance system with compulsory and voluntary health insurance. Thus, the National Health Insurance Fund was established. The Fund is the only institution responsible for social health insurance. The structure of the fund includes a head office in Sofia, 28 branches (one in each province - the Regional Health Insurance Fund) and 105 municipal offices.

Health services in Turkey are carried out under the General Health Insurance covered by the state guarantee. However, despite the existence of a mixed health system in Bulgaria, it has been observed that most of the health services are provided by the Health Fund, which is an independent structure, under the control of the Ministry of Health. According to the structure of the Health Fund in Bulgaria, individual health contracts are made and individuals who do not pay their premiums cannot benefit from health services.

\section{Giriş}

Sağlık sistemi kavramı, sağlık hizmetlerinin sunumu, finansmanı ve hizmetin içeriği, sağlık insan gücünün planlanması, eğitimi ve işe yerleştirilmesi, sağlıkla ilgili yasal düzenlemelerin ve politikalarının belirlenmesi olmak üzere ülkedeki bileşenlerin tamamını tanımlanmaktadır. Ülkelerin sağık sistemlerinin özellikleri, sağlık hizmetlerinin finansmanını şekillendirmekte ve sağılı göstergelerini etkileyen en önemli bileşenlerden biri olarak ön plana çıkmaktadır (Akbolat, 2017; Daştan ve Çetinkaya, 2015).

Günümüzde ülkeler, sağlık sistemleriyle ilişkili farklı yaklaşımlar benimsemektedirler. Bazı ülkelerde sağlık hizmetlerinin finansmanı tümüyle devlet tarafından sağlanırken, bazı ülkelerde ise başta tedavi edici sağlık hizmetleri olmak üzere, tamamıyla serbest piyasa koşullarına bırakıımıştır. Bununla birlikte, çoğu ülkede ise sağlık sistemi karma bir yapıda, yani hem devlet finansmanıyla hem özel sektör tarafından bir arada sunulmaktadır (Akbolat, 2017; Daştan ve Çetinkaya, 2015; World Health Organization [WHO], 2012).

Günümüzde ülkeler hem toplum sağlığını sürdürmek hem de toplum sağlığını koruyarak sağlık harcamalarını azaltabilmek için sağlık sistemleri geliştirmişlerdir. Bu sistemleri birbirinden farklı kılan temel değişkenler ise sağlık hizmetlerini oluşturan kaynakların finansmanı, örgütlenmesi, sunumu ve yönetimidir (Daştan ve Çetinkaya, 2015). Tüm dünyada kabul görmüş ve kullanılan dört temel yaklaşım/model vardır. Bunlar; Beveridge modeli, Bismark modeli, ulusal sağlık sigortası modeli ve cepten ödeme modeli olarak belirtilmiştir. Bu modelleri birbirinden ayıran ana farklar; sağlık hizmeti sağlayıcıları, sağlık hizmetinin finansmanı ve sağlık sigortasının finansmanındaki kaynak farkııı̆̆ olmaktadır (Tatar, 2011).

Bu modellerden ilki olan Beveridge modeli, sağlık hizmetinin devlet tarafından vergi yoluyla finanse edilmesiyle, II. Dünya Savaşı sonrası kullanılmaya başlanan bir modeldir. Bu yaklaşımda, sağlık hizmetleri bir kamu malı olarak görülmekte olup buna göre birçok hastane ve klinik devlete ait olmakta ve sağlık çalışanlarının ücretleri devlet tarafından ödenmektedir. 


\section{Sağlık sistemlerinin karşılaştırılması}

Comparison of health systems

Bu yaklaşım günümüzde başta Danimarka, Finlandiya, Norveç, İsveç gibi Kuzey Avrupa ülkelerinde olmak üzere İspanya, İtalya, Portekiz ve Yunanistan gibi birçok Avrupa ülkesinde de kullanılmaktadır (Daştan ve Çetinkaya, 2015).

Bir diğer yaklaşım olarak Bismarck modeli ise, sigorta sistemine dayanmaktadır. Bu modelde oluşturulan sigorta, işveren ve işçilerden kesilen maaş kesintileri ile finanse edilmektedir. Bu yaklaşım günümüzde Avusturya, Hollanda, Belçika, Fransa ve İsviçre olmak üzere birçok ülkede uygulanmaktadır (Tatar, 2011).

Karma yaklaşımda ise özel sağlık hizmeti sunucuları kullanılmakta olup finansmanı ise vatandaşlar tarafından ödenen vergi veya primlerle karşılanmaktadır. Bu yaklaşımı kullanan ülkelere Kanada en iyi örnek olarak verilmektedir (Daştan ve Çetinkaya, 2015; Steinbrook, 2012).

Bu üç yaklaşıma karşı sağlık hizmetinin finansmanın devlet tarafından karşılanamayacak kadar gelir seviyesi düşük ülkelerde sıklıkla benimsediği model ise cepten ödeme yaklaşımıdır. Bunu benimsemiş ülkelerde, satın alma gücü olanlar sağlık hizmetinden yararlanabilmektedir. Bu yaklaşımı kullanan ülkelere Amerika Birleşik Devletleri en iyi örnek olarak verilmektedir (Daştan ve Çetinkaya, 2015).

Günümüzde ülkelerin kullandığı finansman modelleri genel olarak incelendiğinde sağlık sistemlerinin; vergiler, sigorta primleri, cepten yapılan ödemeler, özel sağlık sigortaları olmak üzere finansmanın gittikçe karma bir durum aldığı görülmektedir (Daştan ve Çetinkaya, 2015).

\section{Türkiye'nin Sağlık Sistemi}

Türkiye Cumhuriyeti Anayasası'na göre sağlık hizmetleri, Sağlık Bakanlığının sorumluluğunda, kamu hizmeti niteliğinde olup devletin temel görevlerinden biridir. Sağlık hizmetlerinin sunumu da hem kamu hem yarı kamu hem özel hem de vakıf kuruluşlarınca sağlanmaktadır. Sağlık hizmetlerinin finansmanı ise alınan vergiler, sosyal güvenlik primleri (SGK), özel sigorta primleri veya cepten ödeme yoluyla sağlanmaktadır. Bununla birlikte, 2012 yılından beri tüm vatandaşların Genel Sağlık Sigortası sistemine katılması da zorunlu olmuştur (Comez, Demirkiran ve Bahar, 2020; Daştan ve Çetinkaya, 2015; TC. Sağlık Bakanlığı Faaliyet Raporu, 2018).

“Sağlıkta Dönüşüm Programı” doğrultusunda, nüfusun büyük bir çoğunluğunu kapsayacak şekilde, var olan tüm sosyal sigortalar kurumları, Sosyal Güvenlik Kurumunun çatısı altında tek bir kurumda toplanmıştır. Böylece herkesin sağlık hizmetlerine eşit ve hakkaniyetli erişimi amaçlanmıştır. Bu süreç sonunda, Türkiye'nin büyük oranda devlet tarafından finanse edilen ve sunulan bir sağlık sistemine sahip olması amaçlanmıştır (Koçkaya, Atikeler ve Yenilmez, 2016). Öte yandan, ülkede özel sağlık sigortacılık anlayışı nüfusun çok az bir kısmını kapsamakla birlikte, gelişme göstermektedir. 2012 yılından başlayarak zorunlu olan genel sağlık sigortası, Sosyal Güvenlik Kurumu verilerine göre nüfusun \%99'unu kapsamaktadır. Genel sağlık sigortasına ek olarak bireyler isterlerse özel sağlık sigortası da yaptırabilmektedir. Özel sağlık sigortalarının Türkiye'de gelişimi 1950'li yıllara dayanmaktadır. Bununla birlikte, yasal düzenlemelerin yapılarak uygulamadaki standartların belirlenmesi ile birlikte tamamlayıcı veya destekleyici özel sağlık sigortaları poliçeleri önem kazanmıştır. Özel sağlık sigortalıları nüfusun yaklaşık \%4'üne denk gelmektedir (Uzun Dönemli Sağlık Sigortası Ülke İncelemesi Raporu, 2015).

Türkiye gelişmekte olan ve kendi gelir grubundaki ülkelerle kıyaslandığında sağlık göstergeleri ve giderlerine göre ortalamanın üzerine çıkmayı başarmıştır. Ancak "Ekonomik İş Birliği ve Kalkınma Örgütü (Organisation for Economic Co-operation and Development- OECD)" üyesi ülkelerle karşılaştırıldığında sağlık göstergeleri açısından en olumsuz durumda olan ülkelerden biri konumunda bulunmaktadır. Bununla birlikte, son yıllarda kamunun sağlık harcamalarındaki payının artması, sağlık finansmanı konusundaki riskleri de artırmaktadır (OECD, 2013; TC. Sağlık Bakanlığı Faaliyet Raporu, 2018).

Öte yandan, 2010 yılından başlayarak, Türkiye genelinde uygulanmakta olan aile hekimliği sistemiyle herkesin bir aile hekiminin olması amaçlanmıştır. Böyleye bireylerin yalnızca bir hastalık durumunda değil bütüncül bir yaklaşımla, var olan sağlık koşulları, psiko-sosyal çevresi, akut veya kronik rahatsızlıklarıyla bir bütün olarak değerlendirilmesi hedeflenmiştir (TC. Sağlık Bakanlığı Faaliyet Raporu, 2018).

\section{Bulgaristan'ın Sağlık Sistemi}

Bulgaristan'ın sağlık politikası, Sağlık Bakanlığı tarafından "Ulusal Sağlık Stratejisi” aracılığıyla belirlenmektedir. Bulgaristan Sağlık Bakanlığı, ulusal düzeyde sağlık politikasının belirlenmesinden, sağlık sisteminin genel örgütlenmesi ve işleyişinden sorumludur. Ayrıca, halk sağlığı ile ilgili tüm kararlar, halk sağlığını ilgilendiren diğer tüm bakanlıklarla birlikte alınmakta ve yürütülmektedir. Bölgesel düzeyindeki sağlık politikaları ise "Bölgesel Sağlık Denetim Birimleri” tarafından düzenlenmekte ve uygulanmaktadır. Ayrıca Sağlık Bakanlığı, gerekli insan kaynaklarını planlayıp sağlamaktan, tıbbi bilimlerin geliştirilmesinden ve nüfusun sağlık durumu ve ulusal düzeydeki sağlık uygulamaları hakkında veri toplamak ve sürdürmekten de sorumludur. Bulgaristan'daki tüm üniversite hastanelerinin, uzmanlaşmış hastanelerin, acil tıbbi bakım merkez- 
lerin ve bölgesel hastanelerin \%51 sermeyesi de devlete aittir. (State of Health in the EU Bulgaria Country Health Profile, 2017; TC. Sofya Büyükelçiliği Ticaret Müşavirliği ve TC. Filibe Başkonsolosluğu Ticaret Ataşeliği, 2017).

Bulgaristan'da 1998 yılında kabul edilen "Sağlık Sigortası Kanunu” ile zorunlu ve gönüllü olmak üzere iki farklı sağlık sigortası sistemi oluşturulmuştur. Böylece bağımsız bir "Ulusal Sağlık Sigorta Fonu” kurulmuştur (Şekil 1). Bu fon, sağlık sigortasının işleyişinden sorumlu olan tek kurum olmaktadır. Sigorta sisteminin kapsamında tanı, tedavi ve rehabilitasyon hizmetleri ve sigortalı bireyler için gerekli olan ilaçlar yer almaktadır. Sağlık Bakanlığı ise halk sağlığı hizmetlerini, acil bakım, transplantasyonlar, yatarak tedavi edilen zihinsel hastalara sunulan hizmetleri, hematolojisi ve tüberküloz tedavisi olmak üzere sağlık bakım hizmetlerini sunmak ve finanse etmekle yükümlüdür. Fon, Sofya'da bir merkez ofis olmak üzere her ilde bulunan 28 bölgesel şube ve 105 belediye bürosu şeklinde örgütlenmiştir (State of Health in the EU Bulgaria Country Health Profile, 2017; TC. Sofya Büyükelçiliği Ticaret Müşavirliği ve TC. Filibe Başkonsolosluğu Ticaret Ataşeliği, 2017).

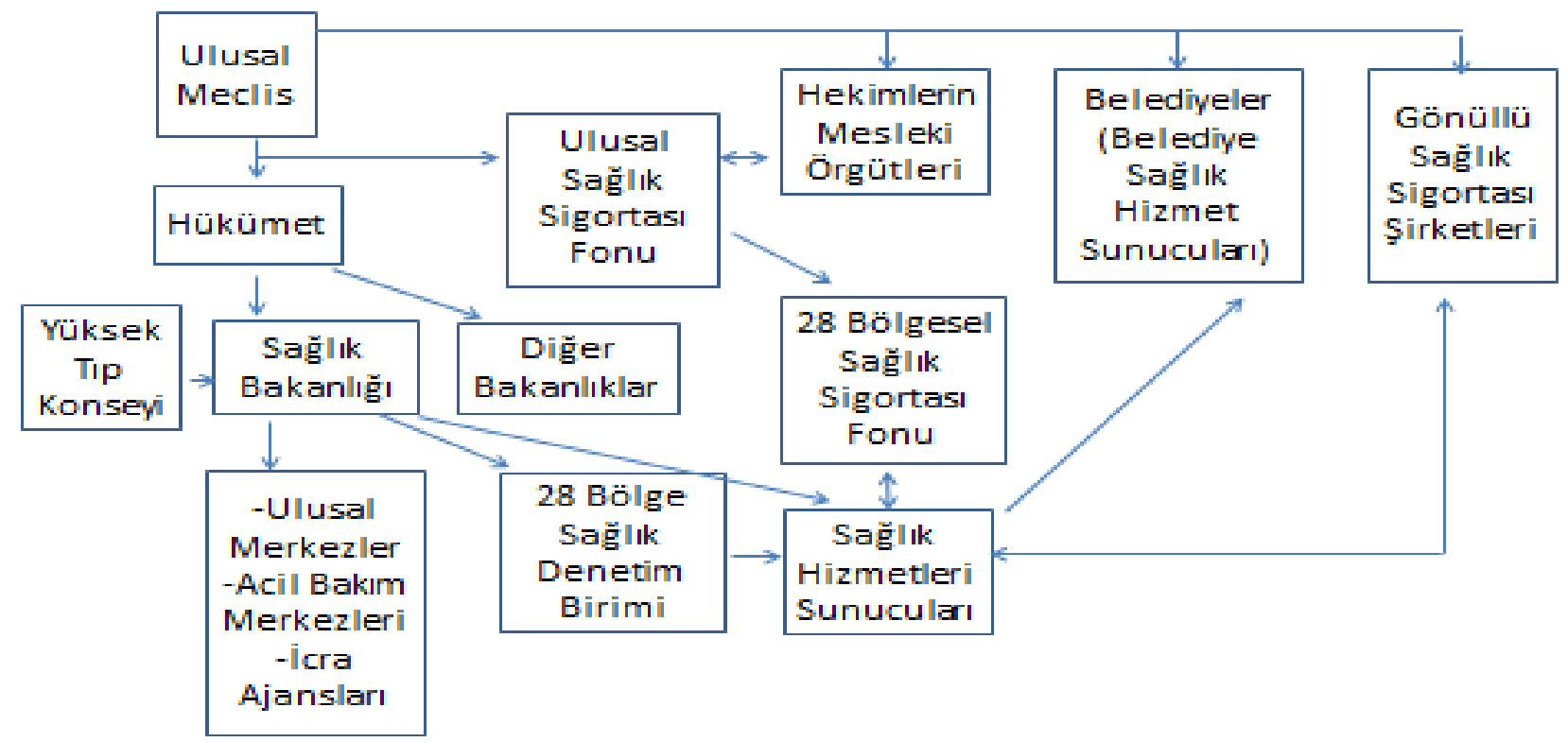

Şekil 1. Bulgaristan sağlık sisteminin örgütlenmesi

Kaynak: State of Health in the EU Bulgaria Country Health Profile (2017). Erişim: 02.12.2020 https://ec.europa.eu/health/ sites/health/files/state/docs/chp_bulgaria_english.pdf

Ulusal Sağlık Sigorta Fonu'nun temel amacı, sigorta yaptıran bireylerin sağlık sistemine eşit erişimini sağlayabilmektir. Bu fon, tıp ve diş hekimliği hizmetleriyle birlikte temel sağlık hizmeti kapsamında bulunan ilaçları da finanse etmektedir. Sağlık hizmetinin içeriği ve fiyatlandırılması, Bulgaristan'daki doktor ve diş hekimlerinin meslek odaları ile fon arasında her yıl yapılan görüşmeler sonucunda "Ulusal Çerçeve Sözleşmesi” ile belirlenmektedir. Bu sözleşmeyle, sağlık hizmeti sunanların ve sigortalı kişilerin hak ve yükümlülükleri, örgütsel prosedürler ve denetim süreçleri belirlenmektedir. Sağlık sunucuları sözleşmeye dayanarak Bölgesel Sağlık Sigortası Fonları aracılığıyla bireysel sözleşmeler imzalayarak hizmetlerini gerçekleştirilmektedir (State of Health in the EU Bulgaria Country Health Profile, 2017; TC. Sofya Büyükelçiliği Ticaret Müşavirliği ve TC. Filibe Başkonsolosluğu Ticaret Ataşeliği, 2017). Bulgaristan'daki acil bakım ve halk sağlığı hizmetleri ise Sağlık Bakanlığı tarafından düzenlenmekte olup finanse edilmektedir. Toplamda 28 bölgede acil bakım merkezi (her ilde bir) bulunmaktadır. Bulgaristan'daki halk sağlığı ağını ise "Ulusal Radyoloji ve Radyasyondan Korunma Merkezi, Ulusal Bulaşıcı Hastalıklar Merkezi, Ulusal Uyuşturucu Bağımlıı̆ı Merkezi, Ulusal Sağlık Enformatiği Merkezi ve Ulusal Halk Sağlığını Koruma Merkezi” vb. oluşturmaktadır (State of Health in the EU Bulgaria Country Health Profile, 2017; TC. Sofya Büyükelçiliği Ticaret Müşavirliği ve TC. Filibe Başkonsolosluğu Ticaret Ataşeliği, 2017).

Bulgaristan'da zorunlu olan sunulan ulusal sağlık sigorta sistemine ek olarak özel sağlık sigortası sistemi de bulunmaktadır. Bireylerin gönüllü olarak yaptırdığı bu özel sağlık sigortası, farklı tıbbi paketleri içermektedir. Bunlardan bazıları yurt dışında yapılacak tedaviyi de kapsayabilmektedir. Bu sigorta paketlerinin fiyatı, rekabet koşulları da dikkate alınarak, paketin türü ve kapsamına göre değişebilmektedir. Bulgaristan'daki yerel özel sağlık sigortaları devletin ödemediği hasta paylarının ödenmesi şeklinde, tamamlayıcı sigorta sistemi olarak yapılanmaktadırlar. Ülkedeki yerel sigorta şirketleri, yalnızca acil durumlardaki yurtdışı harcamalarını kapsamakta, ülke dışında gerçekleştirilen rutin tedaviler ise karşılanmamaktadır. Diğer yandan, Bulgaristan'daki uluslararası sigorta şirketleri ise daha geniş kapsamlı hizmet sunmakta olup (worldwide, global 
benefits, axa gibi), dünyadaki tüm sağlık harcamalarını karşılamaktadırlar (State of Health in the EU Bulgaria Country Health Profile, 2017; TC. Sofya Büyükelçiliği Ticaret Müşavirliği ve TC. Filibe Başkonsolosluğu Ticaret Ataşeliği, 2017).

\section{Türkiye ve Bulgaristan'ın Sağlık Sistemlerinin Karşılaştırılması}

İki ülkenin sağlık sistemleri kıyaslandığında, Türkiye'de Genel Sağlık Sigortası kapsamında sağlık hizmetlerine ulaşımın devlet güvencesi kapsamında tüm vatandaşlara ulaştırılmasının amaçladığı görülmektedir. Bununla birlikte, Türkiye'de maaştan yapılan kesintiler, ödenen primler ve devlet finansmanı ile sağlık hizmetlerinin sunumunun büyük bir kısmının devlet tarafından yürütüldüğü, ancak \%4'lük bir kısmının özel sağlık sigortası ile yürütülen karma bir sağlık finansman sisteminin var olduğu görülmektedir. Buna karşın, Bulgaristan'da da karma yapıda bir sağlık sisteminin var olmasına karşı sağlık hizmetlerinin büyük bir bölümünün Sağlık Bakanlığının denetiminde ve bağımsız bir yapı olan Ulusal Sağlık Sigorta Fonu ile karşılandığı görülmüştür. Bulgaristan'daki bu fonun yapısına göre bireysel sağlık sözleşmeleri yapılmakta ve ödemesini yapmayan ya da yapamayan düşük gelirli bireyler sağlık hizmetlerinden yararlanamamaktadırlar (Sağlık İstatistikleri Yıllığı 2017 Haber Bülteni, 2017; State of Health in the EU Bulgaria Country Health Profile, 2017). Bu bağlamda, Türkiye'de sağlık hizmetinin devlet güvencesi kapsamında tüm vatandaşlara ulaştırılması amaçlanırken, Bulgaristan'da sağlık hizmetinin devlet sorumluluğundan çok bireylerin ödediği bireysel primler ile satın alındığı söylenebilir.

Tablo 1. Türkiye ve Bulgaristan'ın sağlık göstergelerinin karşılaştırılması-2017

\begin{tabular}{|c|c|c|c|c|}
\hline \multicolumn{2}{|l|}{ Değişkenler } & Bulgaristan & Avrupa Birliği & Türkiye \\
\hline \multicolumn{2}{|c|}{ Nüfusun Büyüklüğü } & 7,178 milyon & 512,6 milyon & $80,810,525$ \\
\hline \multicolumn{2}{|c|}{65 yaş ve üstü nüfus oranı (\%) } & 20,0 & 18,9 & 8,5 \\
\hline \multicolumn{2}{|c|}{$0-14$ yaş nüfus oranı (\%) } & 14,1 & - & 23,6 \\
\hline \multicolumn{2}{|c|}{ 15-49 yaş arası kadın başına düşen çocuk sayısı } & 1,5 & 1,6 & 2,1 \\
\hline \multicolumn{2}{|c|}{ Kişi başına düşen toplam sağlık harcaması } & 1.117 Dolar & 2.797 Dolar & 1.124 Dolar \\
\hline \multicolumn{2}{|c|}{ Doğumda beklenen yaşam süresi } & 74,7 & 80,6 & 78,0 \\
\hline \multicolumn{2}{|c|}{ Bebek ölüm hızı (1.000 canlı doğumda) } & 6,6 & 3,5 & 9,1 \\
\hline \multicolumn{2}{|c|}{ Sezaryen doğum (\%) } & 40 & 28 & 54,2 \\
\hline \multicolumn{2}{|c|}{ Tütün kullanımı (\%) } & 28 & - & 26,5 \\
\hline \multicolumn{2}{|c|}{ Alkol kullanımı (\%) } & 17 & - & 12,2 \\
\hline \multicolumn{2}{|c|}{ AIDS (100.000 nüfusta) } & - & 0,7 & 0,1 \\
\hline \multirow[t]{4}{*}{ Hastane sayısı } & Kamu & 214 & - & 879 \\
\hline & Üniversite & - & - & 68 \\
\hline & Özel & 108 & - & 571 \\
\hline & Toplam & 322 & - & 1,518 \\
\hline \multicolumn{2}{|c|}{ 10.000 Kişiye düşen hastane yatağı } & 72,7 & 51,4 & 27,9 \\
\hline \multicolumn{2}{|c|}{100.000 kişiye düşen toplam hekim sayısı } & 435 & 378 & 186 \\
\hline \multicolumn{2}{|c|}{100.000 kişiye düşen diş hekim sayısı } & 127 & 77 & 35 \\
\hline \multicolumn{2}{|c|}{100.000 kişiye düşen ebe-hemşire sayısı } & 480 & 914 & 272 \\
\hline
\end{tabular}

- =veri yok

Türkiye ve Bulgaristan'ın nüfusu ve sağlık göstergeleri kıyaslandığında (Tablo 1), 65 yaş ve üstü nüfusun Bulgaristan'da \%20 oranında ve Türkiye'deki $(\% 8,5)$ orandan en az üç kat fazla olduğu, buna karşın 0-14 yaş arası genç nüfusun ise Türkiye'nin yarısı kadar olduğu belirlenmiştir. Bununla birlikte, kişi başına düşen toplam sağlık harcaması ile doğumda beklenen yaşam süresinin birbirine yakın olduğu görülmektedir. Türkiye'de 1.000 canlı doğumda bildirilen bebek ölüm oranının 9,1 iken Bulgaristan'da 6,6'dır. Ayrıca, Bulgaristan'daki sezaryen oranın Avrupa Birliği ülkelerine kıyasla daha yüksek olmasına karşın, Türkiye'den daha düşük olduğu görülmüştür. İki ülke arasında tütün kullanım oranları birbirine yakınken, alkol kullanım oranının Türkiye'de daha düşük olduğu saptanmıştır. Türkiye'deki toplam hastane sayısının belirgin bir farkla Bulgaristan'dan çok fazla olduğu belirlenirken, 10.000 kişiye düşen hastane yatağı ve 100.000 kişiye düşen hekim, diş hekimi, ebe ve hemşire sayısının çok daha az olduğu görülmüştür (Sağlık İstatistikleri Yıllığı 2017 Haber Bülteni, 2017 ; State of Health in the EU Bulgaria Country Health Profile, 2017). Böylece, Türkiye'nin daha genç bir nüfusa sahip olduğu ve Türkiye'deki hastane sayısının daha fazla olmasına karşın, kişi başına düşen hastane yatak sayısı ve sağlık çalışanı oranının Bulgaristan'a oranla daha düşük olduğu belirtilebilir. 


\section{Sağlık sistemlerinin karşılaştırılması}

Comparison of health systems

İki farklı ülkenin sağlık sisteminin karşılaştıııması; sağlık hizmetinin sunumu, finansmanı, hizmetin kapsamı, sağlık mevzuatı, sağlık politikaları, sağlık insan gücü ve sağlık göstergeleri arasındaki farklılık ve benzerliklerin ortaya konması açısından önemli bir bilgi kaynağı sağlamaktadır. Bu bilgilerin ayrıntı ele alınması, iki farklı ülke ve toplumun sağlık sistemleri ve sağlık göstergelerindeki güçlü ve zayıf yönlerini ortaya koymada, bununla birlikte fırsat ve tehditlerini görülmesine katkı sağlayacaktır.

\section{Sonuç ve Öneriler}

Türkiye ve Bulgaristan'ın sağlık sistemlerinin karşılaştıııldığı bu çalışmada; Türkiye'nin Genel Sağlık Sigortası kapsamında koruyucu, tedavi edici ve bakımın sürdürülmesine ilişkin hizmetlerin Sağlık Bakanlığı, tarafından yürütüldüğü görülmektedir. Sağlık hizmetlerine erişimin devletin sorumluluğunda yürütülmesiyle birlikte Türkiye'de özel hastane ve özel sağlık sigortası kavramının da geliştiği görülmektedir. Öte yandan, Bulgaristan'da sağlık hizmeti sunumunun bağımsız bir kuruluş olan Ulusal Sağlık Sigorta Fonu kapsamında bireyin ödediği primler ve satın aldığı sağlık paketi kapsamında sağlandığı belirlenmiştir. Türkiye ve Bulgaristan'ın nüfusu ve sağlık göstergeleri kıyaslandığında ise Türkiye'nin daha genç bir nüfusa ve daha fazla hastane sayısına sahip olduğu, bununla birlikte, Türkiye'deki kişi başına düşen hastane yatak sayısı ve sağlık çalışanı oranının Bulgaristan'a oranla daha düşük olduğu belirlenmiştir.

Bu çalışmanın, sağık hizmetlerinin kıyaslanması açısından daha ayrıntı ele alınarak ve bilimsel veriler doğrultusunda değerlendirilerek sağlık sistemlerinde yapılacak iyileştirme çalışmalarda dikkate alınması gerektiği belirtilebilir.

Çıkar Çatışması: Bildirilmemiştir.

Finansal Destek: Yoktur.

Conflict of Interest: Not reported.

Funding: None.

\section{Kaynaklar}

Akbolat, M. (2017). Karşılaştırmalı sağlık sistemleri dünya sağlık sistemlerine genel bir bakış ve uygulanmakta olan sağlık sistemi modeller. https://docplayer.biz.tr/23536708-Karsilastirmali-saglik-sistemleri-dunya-saglik-sistemlerine-genel-bir-bakis-ve-uygulanmakta-olan-saglik-sistemi-modelleri.html (Erişim: 24.11.2020)

Comez, M. S., Demirkiran, H. \& Bahar, I. (2020). Should health services be centralized and free in pandemics? The case of Turkey as an example. Archives of Pulmonology and Respiratory Care, 6(1), 087-089. https://www.peertechzpublications.com/articles/APRC-6-164.php (Erişim: 24.11.2020) https://doi.org/10.17352/aprc.000064

Daştan, İ. \& Çetinkaya, V. (2015). OECD ülkeleri ve Türkiye'nin sağlık sistemleri, sağlık harcamaları ve sağlık göstergeleri karşılaştırması. Sosyal Güvenlik Dergisi, 5(1), 104-134.

Koçkaya, G., Atikeler, K. \& Yenilmez, F. B. (2016). Türkiye özel ve kamu sağlık sigortacılığı prim hasar sağlık harcaması değerlendirmesi. Sosyal Güvence, 9, 82-101. https://doczz.biz.tr/doc/41862/sosyal-g\%C3\%BCvence-dergisi-9.-say\%C4\%B1---sosyal- (Erişim: 24.11.2020) https://doi.org/10.21441/sguz.2016917923

Organisation for Economic Co-operation and Development (OECD) (2013). Life expectancy in the us rising slower than elsewhere, says OECD. http://www.oecd.org/unitedstates/Health-at-a-Glance-2013-Press-Release-USA.pdf. (Erişim: 24.11.2020)

Organisation for Economic Co-operation and Development (OECD)/European Observatory on Health Systems and Policies (2017). Bulgaria: Country Health Profile 2017, State of Health in the EU. https://ec.europa.eu/health/sites/health/files/state/docs/chp_bulgaria_ english.pdf (Erişim: 24.11.2020)

Steinbrook, R. (2012). The US supreme court's ruling on the patient protection and affordable care act. BMJ: British Medical Journal, 344, 1-2. https://doi.org/10.1136/bmj.e4503

Tatar, M. (2011). Sağlık hizmetlerinin finansman modelleri: Sosyal sağlık sigortasının Türkiye'deki gelişimi. Sosyal Güvenlik Dergisi, (1), 103-130.

TC. Sağlık Bakanlığı (2018). 2018 yılı faaliyet raporu Erişim: https://dosyamerkez.saglik.gov.tr/Eklenti/34225,tc-saglik-bakanligi-faaliyet-raporu-2018pdf.pdf?0\&_tag1=D41FAD613499B70338F7A1337C05BF50936BB04F (Erişim: 24.11.2020)

TC. Sağlık Bakanlığı Sağlık Bilgi Sistemleri Genel Müdürlüğü (2018). Sağlık istatistikleri yıllığı 2017 haber bülteni. https://dosyamerkez. saglik.gov.tr/Eklenti/27344,saglik-istatistikleri-yilligi-2017-haber-bultenipdf.pdf?0 (Erişim: 24.11.2020) 
TC. Sofya Büyükelçiliği Ticaret Müşavirliği ve TC. Filibe Başkonsolosluğu Ticaret Ataşeliği (2017). Bulgaristan Sağlık Sektörü. https://ticaret. gov.tr/data/5b8a43355c7495406a2276c0/2017_Bulgaristan_Saglik.pdf (Erişim: 24.11.2020)

Türkiye Sigorta Birliği (2015). Uzun dönemli sağlık sigortası ülke incelemesi raporu. https://www.tsb.org.tr/Document/Yonetmelikler/Uzun_ D\%C3\%B6nemli_Sa\%C4\%9FI\%C4\%B1k_Sigortas\%C4\%B1-F\%C4\%B0NAL.pdf (Erişim: 24.11.2020)

World Health Organization (WHO) (2012). Spending on health: A global overview. http://www.who.int/ mediacentre/factsheets/fs319/en/ index.html (Erişim: 24.11.2020) 